\title{
RISKY BUSINESS? CONSUMERS' PROPENSITY TO ENGAGE IN ONLINE BANKING SERVICES
}

\author{
Stephen Wang, Taiwan National Ocean University, Taiwan, ROC \\ Maxwell Hsu, University of Wisconsin-Whitewater, U.S.A. \\ Lou E. Pelton, University of North Texas, U.S.A. \\ Annie H. Liu, Victoria University in Wellington, NZ
}

\begin{abstract}
The Internet is an innovative and increasingly popular medium with unique characteristics and features not to be observed in the traditional off-line channels. The use of the Internet is gaining importance across a variety of industries. In the retail banking industry, the appearance of online banking is one of the most influential information and communication technology. Consumers can now conduct financial transactions, automate tedious tasks (e.g., e-payment), access their account information online anytime (Rotchanakitumnuai and Speece, 2004), and keep important account records in an easy-to-track digital format. The term "Internet banking" and "online banking" have been used interchangeably, and they often refer to the instances in which customers engage in an exchange of information and transactions with a bank via the Internet. In general, this new self-service technology may widely imply usage of computers, mobile phones, digital TVs, etc. for accessing Internet branches (Curran and Meuter, 2005; Lawrence et al., 2009; Sayar and Wolfe, 2007).
\end{abstract}

The perceived psychological risk (i.e., anxious, nervous, and uncomfortable) appears to be relatively more important than other dimensions of the perceived risk concept and this finding points out people's increasing concern over the protection of their financial assets in the networked world. Banks that are sensitive to privacy concerns should display up-to-date privacy policies and avoid sending its customers unsolicited e-mail. Since the complex functionality of the Internet security features may be beyond the scope of a typical online banking customer's technological understanding (Grabner-Kräuter and Faullant, 2008), bank managers should translate the sophisticated security advances to understandable marketing promotions with the goal to influence their customers' risk perception. As online banking risks (e.g., identity theft) are likely to remain when we move toward the digital environments, bank managers need to update banking system's security system and prevent their employees from unwittingly sharing individual customers' personal data with unauthorized entities. Consequently, online banking users' psychological risk and private risk could be dramatically reduced.

Safe banking online needs to start with good decision-making - decisions that will prevent an Internet banking user from costly surprises or even scams. If customers are seriously concerned with the risk perception involved in online banking services, the result may be that they stop using the OBS. In this event, banks would not be able to maximize the potential of their online banking offerings. Only when a bank's online information infrastructure is reliable and has the capacity to recover from malicious attacks, the bank's marketing planners can apply the principles discussed in this paper to their online marketing communications and figure out a way to convert potential OBS customers to loyal consumers.

References Available Upon Request 